\title{
Preface: An Unequal World
}

\author{
Michal Apollo and Pahlaj Moolio
}

\section{Understanding Poverty and Development}

This book seeks to provide interdisciplinary (nay, rather multidisciplinary) perspectives on poverty and development. The Cambridge Dictionary defines the word 'poverty' in simple terms as the condition of a person being poor. Classically, two major traditions for defining poverty are notable: relative and absolute. Relative poverty is defined as the state of having inadequate resources to maintain an acceptable way of living (Townsend, 1979); absolute poverty is a condition characterised by severe deprivation of basic human needs. The multidimensional definition of poverty was adopted in Copenhagen in 1995. It denotes a state in which poor people experience various conditions in their daily lives, such as poor health, lack of education, inadequate housing, limited access to clean water and healthy food, disempowerment, poor quality of work, the threat of violence, and living in areas that are environmentally hazardous, among others. Thus, poverty can exist in social, economic and political terms (see Pogge, 2010; Sachs, 2015).

It is generally agreed that development deals with the alleviation (or eradication) of poverty. Poverty and development have been interconnected since time immemorial (see, for example, Landes, 1998). It could also be argued that development is associated with improvements positive changes in poverty levels, income equality and employment (Seers, 1969) or economic growth (Sachs, 2005), for instance. Furthermore, development can also encompass quality of life, which includes objective well-being (e.g. work, leisure, education) and subjective well-being (e.g. values, expectations). Additionally, development can be viewed as a philosophy in which a society looks forward to a desirable state, a process through which that state is achieved, an outcome of that process or the plan guiding the society to attain its desirable state (Sharpley et al., 1992). More broadly, Arbab (1984) argues that development should be a 'peoplecentered' model for a scientific practice that supports tolerance, sustainability, peace and justice for all.

Contributing to this debate is Amartya Sen's Development As Freedom, which moves beyond the dominant developmental paradigm by asserting the need for a new means of interpreting the relationships 
between a set of linked freedoms: political freedoms and transparency in relations between people, freedom of opportunity and economic protection from abject poverty. Sen (1999: 8) argues that poverty is characterised by the lack of at least one of these freedoms. In essence, Sen takes 'a view of development as an integrated process of expansion of substantive freedoms that connect with one another'. According to Sen, these freedoms are access to healthcare, education, political dissent, economic markets and equality, and each freedom encourages the development of another. Sen depicts the process of the 'expansion of substantive freedoms' as 'both an ends and a means of development', and therefore promotes a dialectical understanding of development, whereby political, economic and social freedoms 'link with each other and with the ends of enhancement of human freedom in general' (1999: 10).

Thus, it is widely agreed that both poverty and development are multidimensional and complex. Additionally, both poverty and development are very broad topics about which much has been said and written (see, for example, Hall \& Patrinos, 2012; Holden, 2013; Payne \& Phillips, 2010; Pogge, 2008; Sachs, 2015). These topics can therefore be considered so extensive that limiting them to a specific definition would be a big mistake (see, for example, Bourguignon \& Chakravarty, 2019).

Similarly, development is often assumed to be socioeconomically, politically or scientifically and technologically biased. Arguably, the concept of development is a complex one. Not only is it difficult to describe, but it is also hard to measure (Oyeshola, 2007). Thus, what does development mean?

Everyone, or almost everyone, is in favour of development. Often, people use this word as a slogan for what they simply consider to be good (Payne \& Phillips, 2010). Arndt (1989) notes that if you ask educated citizens from both developed and developing countries what they understand to be the desirable purpose of the development process, you will receive astonishingly different answers. Development, therefore, must be adapted to the type and character of poverty. Most importantly, this development has to be sustainable. Thus, sustainable development is the central challenge of our times (see, for example, Sachs, 2015). Unfortunately, following the rules of sustainable development to fight against poverty is not easy. As Pogge mentions, the system we live under is designed by the rich for the rich (Duarte, 2016), and because of that, the fight is full of traps. However, in order to fight and conquer poverty, we need to focus on current problems and foresee future ones.

\section{Structure and Intention of this Book}

This book aims to bring together interdisciplinary (indeed, multidisciplinary) perspectives to broaden our understanding of poverty. We invited authors to submit both empirical and conceptual chapters on a 
range of topics related to the impact of poverty on sustainable development, including but not limited to the following:

- natural or social changes in the environment caused directly or indirectly by people, which pose an existential risk to humans, especially to those living in countries of the Global South;

- the natural, social and economic aspects of human behaviour and environmental sustainability;

- the impact of global warming on various aspects of human well-being, including immigration and integration policies, especially as seen through local and regional lenses;

- impact assessments of the environmental consequences (both positive and negative) of industry, agriculture and services (e.g. tourism) in terms of natural, social or economic aspects;

- new concepts in tourism development that consider tourism to be one of the key contributors to the prosperity and well-being of all stakeholders, especially in the countries of the Global South;

- overconsumption in the context of human behaviour and its impact on sustainable development.

The book is a collection of 15 chapters by international scholars who represent a wide range of academic disciplines. It is thus not only interdisciplinary but can also provide the reader with a broad perspective on poverty and development. The book is divided into two parts. The first part presents poverty and development issues from a global perspective while the second part offers local perspectives.

The first chapter deals with the management of ecosystem services. Celina Aznarez argues that unequal access to ecosystem services constitutes one of the main environmental problems - a source of ecologicaldistributive conflict in a society organised around scarce resources. The second chapter, written by Agnieszka Legut, explores climate change induced migration based on a review of the literature and an EU case study. Her analysis shows that there has been no comprehensive policy development at the EU level regarding the phenomenon in question, but rather only references scattered across a number of policy fields, and the widely contested 'climate refugee' term is avoided. Chapter 3 covers another quality that it is essential to consider in the study of modern civilisation: uncontrolled urbanisation. Małgorzata Kmak proves that the slogan of sustainable development, so popular in planning documents, is not implemented in practice at all. In Chapter 4, Urszula Śliwka explains that nutritional deficiencies affect not only the Global South but also the Global North. She argues that overconsumption of calories can occur alongside poor nutrient intake and malnutrition due to a lack of essential micronutrients. The next three chapters concern tourism, which is universally known to be a significant catalyst for economic growth and job creation. However, as Agnieszka Gawlik explains in Chapter 5, contemporary 
tourism, which is the source of various benefits, causes different kinds of costs to the economy, society and the environment. She proposes an evaluation criterion that should be used in the formulation, realisation and identification of the impact of sustainable tourism policy. Chapter 6 explores the concept of slow tourism. Ozan Kaya shows that slow tourism has great potential for sustainable development and poverty reduction through regular income distribution, low-carbon travel and accommodation, and practices that ensure/support the use of local production and agriculture. Chapter 7, co-authored by Agnieszka Gawlik and Barbara Woś, describes agritourism and ecotourism as innovative directions for sustainable rural development. The authors show that agri- and ecotourism generate significant contributions to the process of sustainable rural development with specific effects on the environment, agricultural heritage or economic growth. Chapter 8 again delves into agriculture; however, this time the perspective is economic. The work of Rashedul Hasan, Mohammad Dulal Miah and Muhammad Ashfaq provides valuable findings for emerging economies and specifies policy recommendations by endorsing the role of central banks to implement an agriculture-friendly credit policy to maintain sustainable economic development.

The second part of the book contains seven chapters that focus on specific case studies; all of the research was preceded by insightful background work. Chapter 9, by Van Canh Truong, focuses on measuring sustainable development. Using Vietnam as a case study, Truong stresses that a proper evaluation of sustainable development is needed to meet the needs of the present without compromising the ability of future generations to meet their own needs. In Chapter 10, Cristina Ghinea and Ancuța Elena Prisacaru look at sustainable consumption based on a survey conducted in Romania. The authors indicate that there was a high level of knowledge about sustainable consumption among respondents, but a moderate attitude and practice level. Thus, they recommend moving from theory to practice. Chapter 11 focuses on environmental sustainability concerns. By investigating the environmental consequences of the recent oil spill in the world's largest mangrove forest - the Sundarbans in Bangladesh - Azizul Hassan explains and analyses business models that address environmental sustainability. In Chapter 12, Kennedy Eborka, Chinyere C. Nwokeke and Mosope Akinbola deal with the negative consequences of urbanisation. The researchers from Lagos focus on access to affordable housing and sustainable development among low-income earners in Nigeria. Based on their recommendations, governments should shift from the usual elitist approach to the provision of housing and place greater emphasis on housing units for low- and medium-income earners. Chapter 13 returns us to Nigeria, and Chinyere C.P. Nnorom and Kennedy Eborka discuss the structure of patriarchy and its applications for the exploitation, deprivation and subjugation of females in family and community life. The authors recommend compulsory education for girls up to 
secondary school level, the strengthening of existing legal codes to protect females from all forms of abuse and exploitation, and the introduction of social security for non-working widows and elderly and unemployed women. In Chapter 14, Renata Rettinger explores the present and potential environmental, societal and economic conflicts brewing in tourist regions in the context of sustainable development. Using Cuba as a case study, she claims that, despite the negative issues, tourist enclaves will continue to be built on islands or in spatially isolated geographic areas. Chapter 15, written by Hoang Van Long and Mitsuyasu Yabe, explores environmental factors affecting agricultural production. The authors stress that plant disease, soil fertility, irrigation management and water pollution have negatively affected profit in rice production in Vietnam. In short, farmers should reduce their household size and the number of farm plots, apply a row-seeding technique and improve environmental factors to obtain high-profit efficiency.

Despite the different contexts and discourses of these contributors, each case highlights poverty and development. However, it must be mentioned that it is impossible for even a comprehensive publication to discuss every single challenge that the current world faces. It is also not possible to indicate all future prospects. Nevertheless, the issues presented here are worthy of attention, even if they comprise only a fraction of the whole picture. The works included here are an attempt to cast some light on some dimensions of these topics.

\section{References}

Arbab, F. (1984) Rural University: Learning about Education and Development. Ottawa: International Development Research Centre.

Arndt, H.W. (1989) Economic Development: The History of an Idea. Chicago, IL: University of Chicago Press.

Bourguignon, F. and Chakravarty, S.R. (2019) The measurement of multidimensional poverty. In S.R. Chakravarty (ed.) Poverty, Social Exclusion and Stochastic Dominance (pp. 83-107). Singapore: Springer.

Duarte, M. (2016) Stand against poverty: An interview with Thomas Pogge. Etikk I Praksis 2, 91-108.

Hall, G.H. and Patrinos, H.A. (eds) (2012) Indigenous Peoples, Poverty, and Development. Cambridge: Cambridge University Press.

Holden, A. (2013) Tourism, Poverty and Development. New York: Routledge.

Landes, D. (1998) The Wealth and Poverty of Nations: Why Some Are So Rich and Some So Poor. New York: W.W. Norton.

Oyeshola, D. (2007) Development and poverty: A symbiotic relationship and its implication in Africa. African Journal of Traditional, Complementary and Alternative Medicines 4 (4), 553-558.

Payne, A. and Phillips, N. (2010) Development. Cambridge: Polity Press.

Pogge, T. (2008) World Poverty and Human Rights. Cambridge: Polity Press.

Pogge, T. (2010) Politics as Usual: What Lies Behind the Pro-Poor Rhetoric. Cambridge and Malden, MA: Polity Press.

Pogge, T. (2013) Poverty and violence. Law, Ethics and Philosophy 1, 87-111. 
Sachs, J.D. (2005) The End of Poverty: Economic Possibilities for Our Time. New York: Penguin.

Sachs, J.D. (2015) The Age of Sustainable Development. New York: Columbia University Press.

Seers, D. (1969) The meaning of development. International Development Review 11 (4), 3-4.

Sen, A. (1999) Development As Freedom. New York: Oxford University Press.

Sharpley, A.N., Smith, S.J., Jones, O.R., Berg, W.A. and Coleman, G.A. (1992) The transport of bioavailable phosphorous in agricultural runoff. Journal of Environmental Quality 21, 30-35.

Townsend, P. (1979) Poverty in the United Kingdom. London: Allen Lane and Penguin. 